\title{
Control of the Gas Flow in an Industrial Directional Solidification Furnace for Production of High Purity Multicrystalline Silicon Ingots
}

\author{
Lijun Liu, ${ }^{1}$ Xiaofang Qi, ${ }^{1}$ Wencheng Ma, ${ }^{1}$ Zaoyang Li, ${ }^{1}$ and Yunfeng Zhang ${ }^{2}$ \\ ${ }^{1}$ Key Laboratory of Thermo-Fluid Science and Engineering, Ministry of Education, School of Energy and Power Engineering, \\ Xian Jiaotong University, Xian, Shaanxi 710049, China \\ ${ }^{2}$ Yingli Green Energy Holding Co., Ltd., Baoding, Hebei 071051, China
}

Correspondence should be addressed to Lijun Liu; ljliu@mail.xjtu.edu.cn

Received 30 April 2015; Revised 2 July 2015; Accepted 6 July 2015

Academic Editor: Elias Stathatos

Copyright (C) 2015 Lijun Liu et al. This is an open access article distributed under the Creative Commons Attribution License, which permits unrestricted use, distribution, and reproduction in any medium, provided the original work is properly cited.

\begin{abstract}
A crucible cover was designed as gas guidance to control the gas flow in an industrial directional solidification furnace for producing high purity multicrystalline silicon. Three cover designs were compared to investigate their effect on impurity transport in the furnace and contamination of the silicon melt. Global simulations of coupled oxygen $(\mathrm{O})$ and carbon $(\mathrm{C})$ transport were carried out to predict the $\mathrm{SiO}$ and $\mathrm{CO}$ gases in the furnace as well as the $\mathrm{O}$ and $\mathrm{C}$ distributions in the silicon melt. Cases with and without chemical reaction on the cover surfaces were investigated. It was found that the cover design has little effect on the O concentration in the silicon melt; however, it significantly influences $\mathrm{CO}$ gas transport in the furnace chamber and C contamination in the melt. For covers made of metal or with a coating on their surfaces, an optimal cover design can produce a silicon melt free of $\mathrm{C}$ contamination. Even for a graphite cover without a coating, the carbon concentration in the silicon melt can be reduced by one order of magnitude. The simulation results demonstrate a method to control the contamination of $\mathrm{C}$ impurities in an industrial directional solidification furnace by crucible cover design.
\end{abstract}

\section{Introduction}

Multicrystalline silicon (mc-Si) produced by the directional solidification (DS) method has dominated the photovoltaic market in recent years. However, the concentrations of impurities in $\mathrm{mc}-\mathrm{Si}$ ingots are higher than those in single crystals. This disadvantage leads to mc-Si solar cells having lower efficiency than single crystal solar cells. To improve the efficiency of solar cells, the impurities in mc-Si must be controlled. The main impurities in $\mathrm{mc}$-Si ingots are oxygen (O) and carbon (C). Boron-oxygen complexes acting as recombination centers of photocarriers cause the serious problem of light-induced degradation of solar cells [1]. The $\mathrm{C}$ precipitates in a silicon ingot influence the wafer cutting process and reduce the solar cell efficiency [2]. Therefore, an effective way to control the $\mathrm{O}$ and $\mathrm{C}$ concentrations is essential to produce high purity mc-Si ingots for high efficiency solar cells.
There are various ways to control the concentrations of impurities to produce high purity mc-Si ingots in a DS furnace, such as process optimization and hot-zone design of the furnace. The former method mainly focuses on modifying the growth rate [3], silicon melt convection $[4,5]$, argon gas flow intensity [5-7], and furnace pressure [6-8] rather than influencing the pathway of impurity transport. The latter method redesigns the local configuration of the DS furnace, such as designing gas shields [9-11] and gas injector valve [12], so that the gas flow and the pathway of impurity transport can be controlled. It provides a new concept for impurity control in a DS furnace for mc-Si ingot growth. Recently, Liu et al. [13] pointed out that the silicon melt is severely contaminated by $\mathrm{C}$ impurities from the furnace chamber at the final stage of the melting process. To alleviate $\mathrm{C}$ contamination of the silicon melt before the solidification process, it is essential to control the transport pathway of the impurities in the furnace chamber and prevent them from being transported 


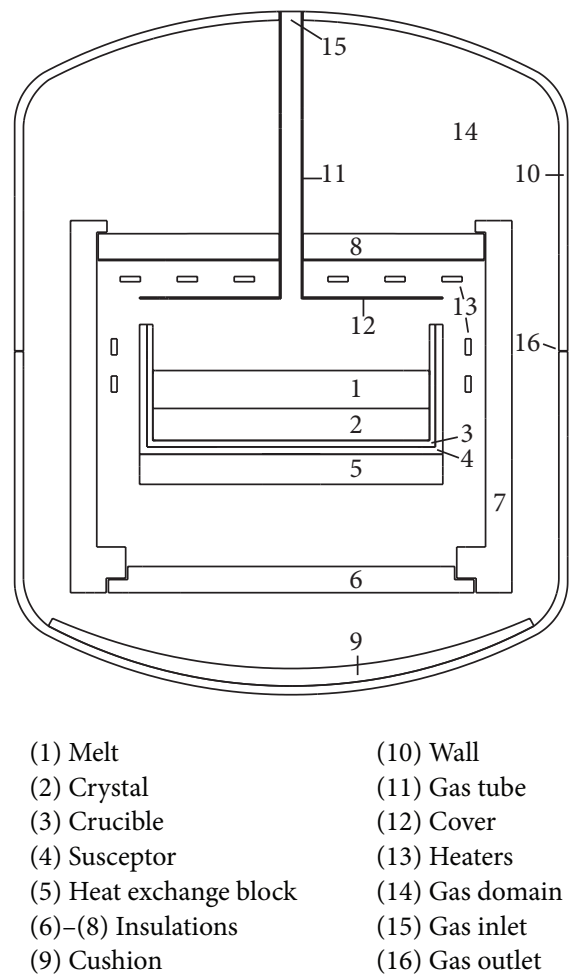

FIGURE 1: Configuration of an industrial directional solidification furnace.

to the silicon melt free surface. For this purpose, in this study a crucible cover was designed as gas flow guidance in the GTS-DSS450 industrial furnace, as shown in Figure 1, which is different from previous furnaces such as GTS-DSS240 and GTS-HEM240 [10]. The cover can regulate the pathway of the argon gas flow in the furnace chamber. Gao et al. [9] numerically investigated the cover's effect on $\mathrm{O}$ and $\mathrm{C}$ transport in a small laboratory-scale DS furnace. However, for an industrial DS furnace such as GTS-DSS450, which can produce a $450 \mathrm{~kg}$ ingot in one run, the cover's effect on impurity transport is still unclear because of the large size and highly complex thermal interactions in the furnace. Very little research has been reported regarding the effect of crucible cover design on impurity transport in such an industrial furnace.

In this paper, the industrial DS furnace GTS-DSS450 was used to numerically investigate the effect of the cover design on the argon gas flow and coupled oxygen/carbon transport in the furnace chamber as well as the contamination of impurities in the silicon melt. All thermal interactions, such as melt convection, argon gas flow, solid conduction, thermal radiation, and phase change, were included in the global simulations. The main chemical reactions of $\mathrm{O}$ and $\mathrm{C}$ in the DS furnace were considered. This study provides a possible way to produce high purity $\mathrm{mc}$-Si ingots through the optimal design of the crucible cover in an industrial DS furnace.

\section{Model Description}

2.1. Models of Global Heat Transfer and Coupled Oxygen/Carbon Transport. Global modeling, including melt convection, argon flow, solid thermal conduction, and thermal radiation, was first carried out for the DS furnace. The configuration of the DS furnace to produce $\mathrm{mc}-\mathrm{Si}$ ingots is shown in Figure 1. The furnace is subdivided into a number of subblocks. The structured/unstructured combined mesh scheme is applied. The major assumptions in the model are as follows: (1) the quasi-steady-state assumption is applied, (2) the geometry of the furnace configuration is axisymmetric, (3) radiative surfaces are diffuse-gray, (4) the melt flow is incompressible and the Boussinesq assumption is applicable, and (5) the argon gas in the furnace chamber is ideal and completely transparent. The algorithms for the global modeling of heat transfer in a DS furnace have been described in our previous paper [14]. The low Mach approximation and the ideal gas law are applied to the argon gas. The governing equations for argon gas flow are as follows:

$$
\begin{aligned}
\nabla \cdot(\rho \vec{u})= & 0, \\
\nabla \cdot(\rho \vec{u} \vec{u})= & -\nabla p+\nabla\left(-\frac{2}{3} \mu \nabla \cdot \vec{u}\right)+\nabla \cdot(2 \mu S) \\
& +\left(\rho-\rho_{0}\right) \vec{g}, \\
\nabla \cdot\left(\rho C_{p} \vec{u} T\right)= & \Delta(\lambda T), \\
\rho= & \frac{p_{0}}{R T},
\end{aligned}
$$

where $\rho$ is the argon gas density, $\vec{u}$ is the gas velocity, $p$ is the gas pressure, $\mu$ is the dynamic viscosity, $S$ is the strain rate tensor, $\vec{g}$ is the gravity acceleration vector, $C_{p}$ is the heat capacity, $T$ is the temperature, $\lambda$ is the heat conductivity, $\rho_{0}$ and $p_{0}$ are the reference density and reference pressure, respectively, and $R$ is the specific gas constant, which is $208.1 \mathrm{~J} /(\mathrm{kg} \cdot \mathrm{K})$ for argon gas. In the current simulation, the flow rate and inlet temperature of the argon gas are $20 \mathrm{~L} / \mathrm{min}$ and $300 \mathrm{~K}$, respectively. The furnace pressure is $0.6 \mathrm{bar}$. The temperature of the outer wall of the chamber is taken to be $300 \mathrm{~K}$.

Based on the global thermal and flow fields, the coupled oxygen/carbon transport was simulated. A generally accepted pathway for $\mathrm{O}$ and $\mathrm{C}$ transport in a silicon solidification furnace is as follows $[6,7]$. (1) O dissolves from the quartz crucible wall into the silicon melt through a $\mathrm{Si}_{3} \mathrm{~N}_{4}$ coating. (2) The dissolved $\mathrm{O}$ atoms in the silicon melt combine with a silicon atom and evaporate into the argon gas flow in the form of $\mathrm{SiO}$ gas at the gas/melt interface. (3) $\mathrm{SiO}$ is then carried away by the argon flow to all of the graphite fixture' surfaces and reacts with them to form CO gas. (4) The CO gas is transported back with the argon gas flow to the gas/melt interface and then dissolves into the silicon melt in the form of $\mathrm{C}$ and $\mathrm{O}$ atoms. (5) Finally, the $\mathrm{C}$ and $\mathrm{O}$ atoms in the silicon melt are segregated into the growing crystal. The chemical reaction equations corresponding to the above five reactions have been described in [7]. 
The effects of $\mathrm{O}$ and $\mathrm{C}$ species on the density of the silicon melt were neglected because of their low concentrations. Thus, the governing equations of $\mathrm{O}$ and $\mathrm{C}$ transport in the silicon melt are expressed as

$$
\begin{aligned}
& \nabla \cdot\left(\rho_{\mathrm{Si}} \omega_{\mathrm{O}} \vec{u}_{\mathrm{Si}}\right)=\nabla \cdot\left[\rho_{\mathrm{Si}} D_{\mathrm{O}} \nabla \omega_{\mathrm{O}}\right], \\
& \nabla \cdot\left(\rho_{\mathrm{Si}} \omega_{\mathrm{C}} \vec{u}_{\mathrm{Si}}\right)=\nabla \cdot\left[\rho_{\mathrm{Si}} D_{\mathrm{C}} \nabla \omega_{\mathrm{C}}\right],
\end{aligned}
$$

where $\omega_{\mathrm{O}}$ and $\omega_{\mathrm{C}}$ are the mass fractions of $\mathrm{O}$ and $\mathrm{C}$ atoms in the silicon melt, respectively, $\rho_{\mathrm{Si}}$ is the density of melt, $\vec{u}_{\mathrm{Si}}$ is the velocity of melt, and $D_{\mathrm{O}}$ and $D_{\mathrm{C}}$ are the diffusivities of $\mathrm{O}$ and $\mathrm{C}$ atoms in the melt, respectively. Their values are taken to be $5.0 \times 10^{-8} \mathrm{~m}^{2} / \mathrm{s}[15]$.

The governing equations for the transport of $\mathrm{SiO}$ and $\mathrm{CO}$ species in the argon gas are as follows:

$$
\begin{aligned}
& \nabla \cdot\left(\rho_{\mathrm{Ar}} \omega_{\mathrm{SiO}} \vec{u}_{\mathrm{Ar}}\right)=\nabla \cdot\left[\rho_{\mathrm{Ar}} D_{\mathrm{SiO}} \nabla \omega_{\mathrm{SiO}}\right], \\
& \nabla \cdot\left(\rho_{\mathrm{Ar}} \omega_{\mathrm{CO}} \vec{u}_{\mathrm{Ar}}\right)=\nabla \cdot\left[\rho_{\mathrm{Ar}} D_{\mathrm{CO}} \nabla \omega_{\mathrm{CO}}\right],
\end{aligned}
$$

where $\omega_{\mathrm{SiO}}$ and $\omega_{\mathrm{CO}}$ are the mass fractions of $\mathrm{SiO}$ and $\mathrm{CO}$ in argon gas, respectively, $\rho_{\mathrm{Ar}}$ is the density of argon gas, and $\vec{u}_{\mathrm{Ar}}$ is the argon gas flow velocity. $D_{\mathrm{SiO}}$ and $D_{\mathrm{CO}}$ are the diffusivities of $\mathrm{SiO}$ and $\mathrm{CO}$ in the argon gas, respectively, which are expressed as [2]

$$
\begin{aligned}
& D_{\mathrm{SiO}}=8.62611 \times 10^{-6} \frac{T^{1.75}}{p}, \\
& D_{\mathrm{CO}}=1.79548 \times 10^{-5} \frac{T^{1.75}}{p} .
\end{aligned}
$$

The boundary conditions for the impurity species transport in the silicon and argon gas regions are as follows:

(a) On the inner wall of the quartz crucible, the equilibrium concentration of $\mathrm{O}$ atoms can be expressed as [16]

$$
\begin{aligned}
& c_{0}=0.5 \times 10^{23} \times \frac{a}{1-a} \text { atom } / \mathrm{cm}^{3}, \\
& a=1.32 \times \exp \left(\frac{-7150}{T}-6.99\right) .
\end{aligned}
$$

For the $\mathrm{C}$ atoms at the inner wall of the crucible, a zero flux boundary condition is applied.

(b) At the melt-gas interface, $\mathrm{O}, \mathrm{C}, \mathrm{SiO}$, and $\mathrm{CO}$ coexist. Equilibrium relationships for the same element between the silicon melt and argon gas are given as follows [2]:

$$
\begin{aligned}
& c_{\mathrm{SiO}}=\frac{101325}{R_{g} T} \frac{c_{\mathrm{O}}}{c_{\mathrm{Si}}} e^{-21000 / T+17.8}, \\
& c_{\mathrm{CO}}=\frac{101325}{R_{g} T} \frac{c_{\mathrm{O}}}{c_{\mathrm{Si}}} \frac{c_{\mathrm{C}}}{c_{\mathrm{Si}}} e^{-5210 / T+14.6},
\end{aligned}
$$

where $c_{\mathrm{SiO}}$ and $c_{\mathrm{CO}}$ are the molar concentrations of $\mathrm{SiO}$ and $\mathrm{CO}$ in the argon gas, respectively, $c_{\mathrm{O}}$ and $c_{\mathrm{C}}$ are the molar concentrations of $\mathrm{O}$ and $\mathrm{C}$ in the silicon melt, respectively, and $R_{g}$ is the universal gas constant, which is equal to $8.314 \mathrm{~J} /(\mathrm{mol} \cdot \mathrm{K})$.
Two more boundary conditions are needed to solve for the four unknown variables at the melt-gas interface according to the law of mass conservation:

$$
\begin{aligned}
c_{\mathrm{Ar}} D_{\mathrm{SiO}} \nabla\left(\frac{c_{\mathrm{SiO}}}{c_{\mathrm{Ar}}}\right)+ & c_{\mathrm{Ar}} D_{\mathrm{CO}} \nabla\left(\frac{c_{\mathrm{CO}}}{c_{\mathrm{Ar}}}\right)=c_{\mathrm{Si}} D_{\mathrm{O}} \nabla\left(\frac{c_{\mathrm{O}}}{c_{\mathrm{Si}}}\right), \\
c_{\mathrm{Ar}} D_{\mathrm{CO}} \nabla\left(\frac{c_{\mathrm{CO}}}{c_{\mathrm{Ar}}}\right) & =c_{\mathrm{Si}} D_{\mathrm{C}} \nabla\left(\frac{c_{\mathrm{C}}}{c_{\mathrm{Si}}}\right) .
\end{aligned}
$$

(c) $\mathrm{SiO}$ reacts with carbon at the surfaces of the hot graphite fixtures to generate $\mathrm{CO}$. The reaction is assumed to be reversible and the Gibbs free energy of the reaction is expressed as follows [2]:

$$
\begin{array}{ll}
\Delta G=-81300+3.02 T \mathrm{~J} / \mathrm{mol}, & T<1640 \mathrm{~K}, \\
\Delta G=-22100-33.1 T \mathrm{~J} / \mathrm{mol}, & 1640 \mathrm{~K}<T<1687 \mathrm{~K}, \\
\Delta G=-72100-3.44 T \mathrm{~J} / \mathrm{mol}, & T>1687 \mathrm{~K} .
\end{array}
$$

The equilibrium constant of the reaction is $K=e^{-\Delta G / R T}$. The coupled boundary conditions at the graphite fixture' surfaces can be expressed as

$$
\begin{aligned}
c_{\mathrm{Ar}} D_{\mathrm{SiO}} \nabla\left(\frac{c_{\mathrm{SiO}}}{c_{\mathrm{Ar}}}\right) & =-c_{\mathrm{Ar}} D_{\mathrm{CO}} \nabla\left(\frac{c_{\mathrm{CO}}}{c_{\mathrm{Ar}}}\right), \\
\frac{c_{\mathrm{CO}}}{c_{\mathrm{SiO}}} & =K .
\end{aligned}
$$

(d) At the argon gas inlet, the concentrations of $\mathrm{SiO}$ and $\mathrm{CO}$ are set to zero. At other solid component surfaces, zero fluxes of $\mathrm{SiO}$ and $\mathrm{CO}$ are applied. At the argon gas outlet, zero gradients of $\mathrm{SiO}$ and $\mathrm{CO}$ are used. Zero radial gradients for all the species are applied along the centerline of the fluid regions in the furnace.

The relationship between the mass fraction $\omega$ and the molar concentration $c$ in the aforementioned equations and boundary conditions is $c=\rho \omega / M$, where $M$ is the atomic weight of the impurity species. For the current simulations, the fully molten state (i.e., only the silicon melt exists in the crucible and crystallization has not started) was chosen. The first reason is that it is convenient to analyze the effect of the crucible cover design on the impurity contamination of the silicon melt before the solidification process. Another reason is that there is always a stabilization period in a DS process after the silicon feedstock is melted and before solidification starts in which the thermal system can be treated as quasisteady state.

2.2. Crucible Cover Designs. Three crucible cover designs were selected and their effects on the transport of oxygen and carbon impurities in an industrial DS furnace for growing $\mathrm{mc}-\mathrm{Si}$ were compared. The first design is called the no-cover design. That is, there is no cover on the crucible in the GTS-DSS450 furnace. The second design is the GTS-DSS450 furnace with a flat cover, as shown in Figure 1. The third design is shown in Figure 2, in which the flat cover is replaced by a U-shaped cover (U cover). There are two parameters in the third design: the gap between the melt surface and the 


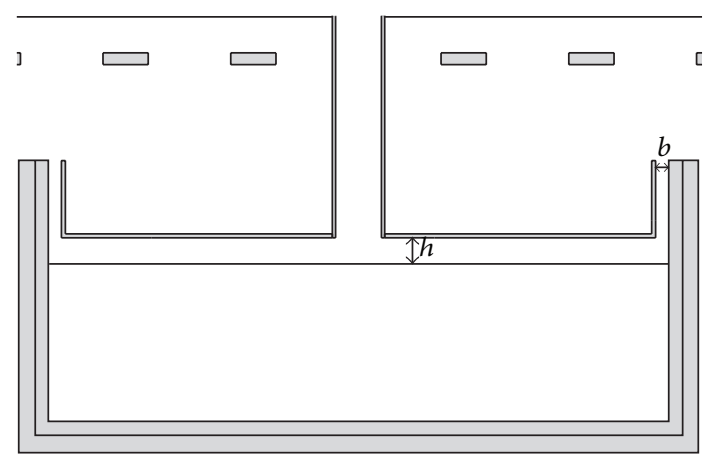

Figure 2: Design of the crucible U cover.

bottom surface of the cover $h$ and the gap between the side surface of the cover and the inside surface of the crucible $b$. For the current designs under consideration, $h$ is $40 \mathrm{~mm}$ and $b$ is $20 \mathrm{~mm}$.

To investigate the effect of the crucible cover design on the contamination of impurities in the silicon melt by the environment in the furnace chamber, the content of impurities in the silicon feedstock was not considered in the simulations. For covers made of molybdenum or graphite with a perfect coating, no chemical reaction occurs on the cover's surface. The hot heaters are the unique $\mathrm{C}$ source in the simulation. If the cover is made of graphite without a coating, $\mathrm{SiO}$ will be consumed on the cover's surface to produce $\mathrm{CO}$ and the cover will be another $C$ source. Both of the above cases will be discussed in the following sections. For all of the simulations, the quartz crucible is the only $\mathrm{O}$ source.

\section{Results and Discussion}

3.1. Comparison of Impurity Transport Pathways. The argon flow pattern and impurity transport pathway in the furnace chamber for the different cover designs were first investigated. Figure 3 shows the stream lines of argon flow above the silicon melt free surface for the different designs. In Figure 3(a), a strong gas recirculation developed in the space above the silicon melt. The impurities evaporated from the melt free surface can be easily taken away, while $\mathrm{CO}$ produced at the hot heaters' surfaces can be transported back at the same time. In Figure 3(b), a flat cover made of molybdenum or tungsten was used and gas recirculation was limited to a smaller area above the melt free surface than with the no-cover design. It is difficult for $\mathrm{CO}$ to be transported back to the gas/melt interface by convection and diffusion. However, gas recirculation under the flat cover may also prohibit impurities that come out of the melt surface from being taken away. In Figure 3(c), gas recirculation in the space between the cover and the melt free surface disappears, leaving only a small backflow eddy. The argon flow can easily take away impurities that evaporate from the melt free surface and prevent $\mathrm{CO}$ from being transported back.

In the above discussion, molybdenum or other materials with high melting points and low chemical activity were used to make the cover an ideal insulator. That is, $\mathrm{SiO}$ does not react with the cover to produce $\mathrm{CO}$. However, a graphite

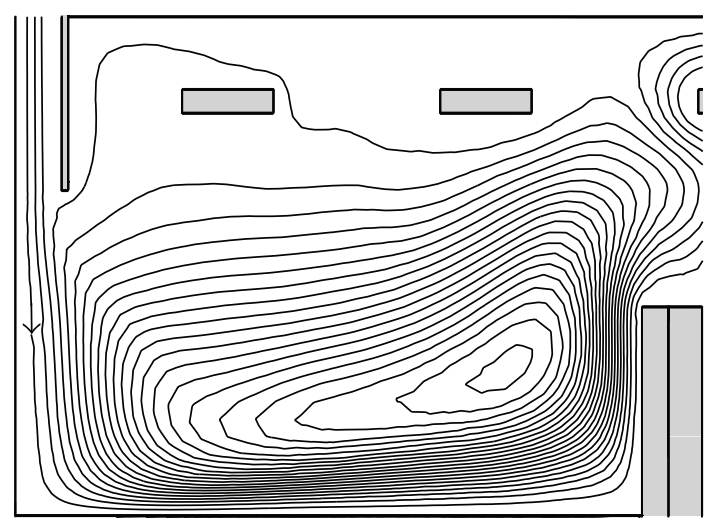

(a)

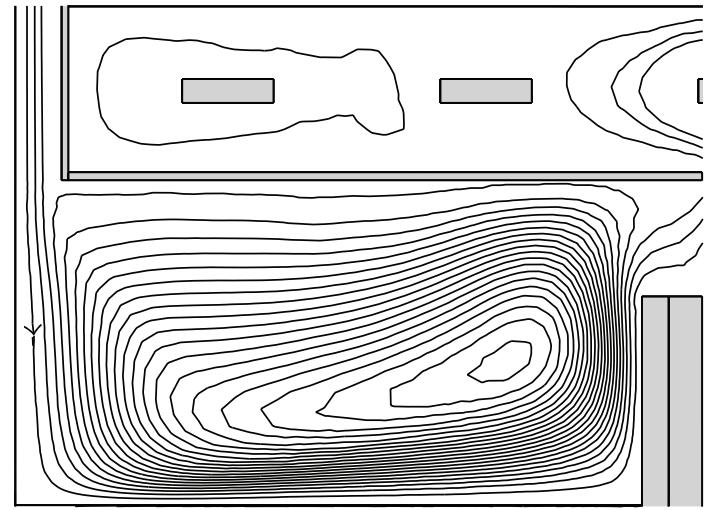

(b)

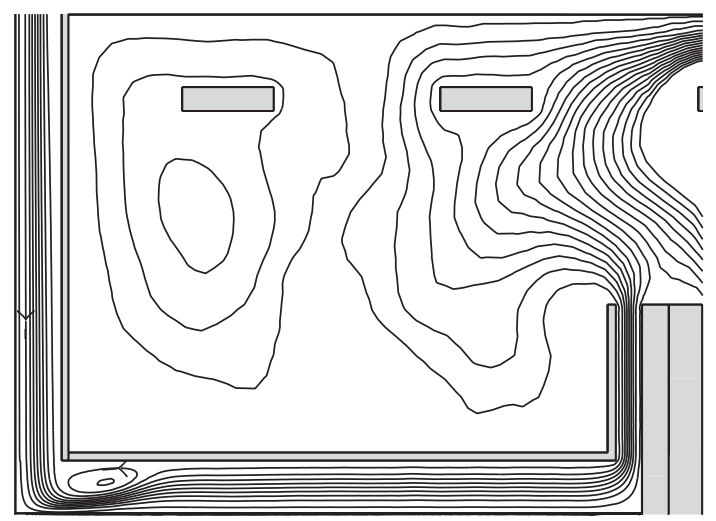

(c)

FIGURE 3: Stream lines above the melt free surface for different cover designs: (a) no cover, (b) flat cover, and (c) U cover.

board with or without a coating is usually used in the actual production process considering the production cost. Even for such a graphite cover with a coating, the coating can be damaged through repeated use. Therefore, cases with chemical reaction occurring on the cover's surface should also be investigated. For the flat-cover design, CO produced at the lower surface of the cover can be transported to the melt free surface by argon gas recirculation. For the U-cover design, there is no gas recirculation above the melt free surface to take back the $\mathrm{CO}$, but the distance between the melt free surface and the cover is small, which makes it easy for 
CO to diffuse from the cover to the melt surface. Therefore, the effects of the different designs on the production of high purity $\mathrm{mc}-\mathrm{Si}$ are not clear.

3.2. Oxygen and Carbon Distributions. The cover is first assumed to be made of molybdenum or other materials with high melting points and low chemical activity. Therefore, no $\mathrm{SiO}$ is consumed and no $\mathrm{CO}$ is produced on the cover's surface. The effects of the different cover designs on the transport of $\mathrm{SiO}$ and $\mathrm{CO}$ in the furnace chamber are compared. Figure 4 shows the distributions of $\mathrm{SiO}$ and $\mathrm{CO}$ above the melt free surface for the different cover designs. Comparing the $\mathrm{SiO}$ distributions in Figures 4(a) and 4(b), the concentrations of $\mathrm{SiO}$ for the no-cover and flat-cover designs are almost the same above the melt free surface. The value is about 1.0 $\times 10^{-9} \mathrm{~mol} / \mathrm{cm}^{3}$. That is, because the flat-cover design only slightly changes the argon flow pattern compared with the nocover design, as shown in Figures 3(a) and 3(b), it has little effect on the evaporation and transport of SiO. However, for the $\mathrm{U}$-cover design, the concentration of $\mathrm{SiO}$ ranges from 1.0 $\times 10^{-11}$ to $1.0 \times 10^{-9} \mathrm{~mol} / \mathrm{cm}^{3}$ in the space between the cover and the melt free surface, as shown in Figure 4(c). The reason for this is that there is no gas recirculation above the melt free surface for such a hot-zone design and no $\mathrm{SiO}$ is carried back. The maximum concentration of $\mathrm{SiO}$ is located at the melt/gas/crucible junction point for all three designs. It is the configuration of the crucible that prevents the argon gas from reaching the junction point, and $\mathrm{SiO}$ evaporated here cannot be easily taken away.

Comparing the CO concentrations in Figure 4(a) with those in Figure 4(b), the cover design has a significant influence on the $\mathrm{CO}$ distributions above the melt free surface. For the no-cover and flat-cover designs, the CO concentrations are in the order of $10^{-10}$ and $10^{-11} \mathrm{~mol} / \mathrm{cm}^{3}$, respectively. The flat-cover design can reduce the $\mathrm{CO}$ concentration by one order of magnitude compared with the no-cover design by preventing $\mathrm{CO}$ produced at the heaters' surfaces from being transported back to the melt free surface. In Figure 4(b), the largest gradient of $\mathrm{CO}$ is located in the space between the crucible top surface and the cover bottom surface, where the distance between the crucible and the cover may play an important role in controlling CO transport. In Figure 4(c), the concentration of $\mathrm{CO}$ at the melt free surface can be reduced to $10^{-29} \mathrm{~mol} / \mathrm{cm}^{3}$ for the U-cover design, which means that it is almost free of carbon. The reasons for this are that the silicon feedstock is assumed to be pure and the hot heaters' surfaces are the only carbon source in the current simulation. In addition, the distance between the inner surface of the crucible and the outside surface of the cover is very small and no gas recirculation occurs in the area between the cover and the melt free surface, both of which make it difficult for CO produced at the heaters' surfaces to be transported back by gas convection or diffusion.

After investigating the effect of the cover design on the distributions of $\mathrm{SiO}$ and $\mathrm{CO}$ in the DS furnace chamber, the concentrations of $\mathrm{O}$ and $\mathrm{C}$ atoms in the silicon melt were compared for the different designs. Figure 5 shows the distributions of $\mathrm{O}$ and $\mathrm{C}$ in the silicon melt for the different cover designs under the same conditions as in Figure 4. The $\mathrm{O}$ concentration in the silicon melt is almost the same for the three designs, and the values range from $10^{16}$ to $10^{17}$ atoms $/ \mathrm{cm}^{3}$. The almost identical values of the $\mathrm{O}$ concentration for the no-cover and flat-cover designs correspond to the similar argon flow patterns and $\mathrm{SiO}$ distributions above the melt free surface, as shown in Figures 4(a) and 4(b). However, for the $\mathrm{U}$-cover design, the $\mathrm{O}$ concentration in Figure 5(c) is close to those in Figures 5(a) and 5(b), while the patterns of argon flow and the $\mathrm{SiO}$ distribution above the melt free surface are quite different to those of the other two designs, as shown in Figures 3 and 4 . This is because of the fact that it is the melt flow rather than the argon gas flow that dominates the transport of $\mathrm{O}$ atoms in the melt. As a result, the cover design has little effect on the $\mathrm{O}$ concentration in the silicon melt. Because the quartz crucible is the only $\mathrm{O}$ source, the maximum concentrations of $\mathrm{O}$ in the silicon melt for the three designs are almost the same. Compared with the effect of the cover design on the $\mathrm{O}$ concentration, the effect on the $\mathrm{C}$ concentration in the silicon melt is significant. The $\mathrm{C}$ concentrations shown in Figures 5(a) and 5(b) are $10^{19}$ and $10^{17}$ atoms $/ \mathrm{cm}^{3}$, respectively. The flat-cover design can reduce the $\mathrm{C}$ concentration in the silicon melt by two orders of magnitude compared with the no-cover design. For the U-cover design, as shown in Figure 5(c), the silicon melt is almost free of $\mathrm{C}$ contamination. Therefore, we can conclude that the $\mathrm{U}$-cover design is the best choice to reduce $\mathrm{C}$ contamination in the silicon melt.

Surface reaction of the crucible cover was not taken into account in the above discussion. However, it is not always consistent with the actual production process, in which the crucible cover is usually made of graphite and $\mathrm{SiO}$ is consumed on the cover's surface to produce CO. In the following discussion, chemical reaction on the cover's surface is considered. Figure 6 shows the distributions of $\mathrm{SiO}$ and $\mathrm{CO}$ above the melt free surface for the different cover designs that take part in the chemical reaction. The $\mathrm{SiO}$ concentrations above the melt free surface in Figures 6(a) and 6(b) are quite different. In Figure 6(a), the $\mathrm{SiO}$ concentration is about $6.0 \times 10^{-10} \mathrm{~mol} / \mathrm{cm}^{3}$ for the flat cover. However, for the $\mathrm{U}$-cover design, the $\mathrm{SiO}$ concentration ranges from $1.0 \times 10^{-12}$ to $1.0 \times 10^{-9} \mathrm{~mol} / \mathrm{cm}^{3}$ in the space between the cover and the melt free surface, as shown in Figure 6(b). This indicates that the U-cover design can still reduce the $\mathrm{SiO}$ concentration near the melt free surface compared with the flat-cover design, even though chemical reaction on the crucible cover's surface exists. Comparing the $\mathrm{SiO}$ concentration in Figure 6(a) with that in Figure 4(b), the $\mathrm{SiO}$ concentration (about $6.0 \times 10^{-10} \mathrm{~mol} / \mathrm{cm}^{3}$ ) above the melt free surface in Figure 6(a) is slightly lower than that in Figure 4(b) (about $1.0 \times 10^{-9} \mathrm{~mol} / \mathrm{cm}^{3}$ ) and the distribution patterns are similar. The reason for this is that the crucible cover chemically reacts and consumes the $\mathrm{SiO}$ gas that evaporates from the melt free surface when the cover is made of carbon material. Therefore, the $\mathrm{SiO}$ concentration shown in Figure 6 is reduced.

For the CO distribution, the U-cover design can still reduce the $\mathrm{CO}$ concentration in the space between the melt 


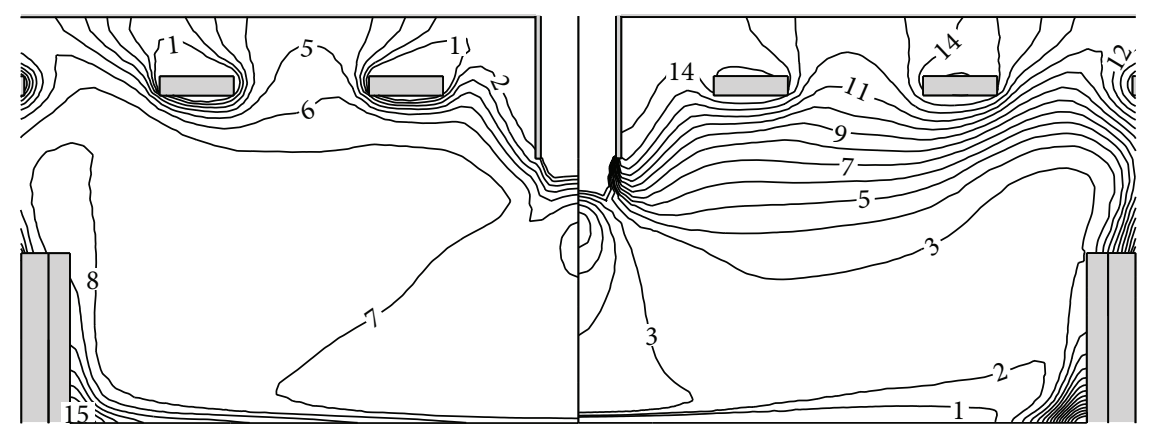

Level of $\mathrm{SiO}\left(\mathrm{mol} / \mathrm{cm}^{3}\right)$

Level of $\mathrm{CO}\left(\mathrm{mol} / \mathrm{cm}^{3}\right)$

$\begin{array}{llllll}\text { (16) } 7.50 E-09 & \text { (10) } 1.76 E-09 & \text { (4) } 4.13 E-10 & \text { (16) } 1.50 E-09 & \text { (10) } 9.67 E-10 & \text { (4) } 6.23 E-10\end{array}$

$\begin{array}{lllllll}\text { (15) } 5.89 E-09 & \text { (9) } 1.38 E-09 & \text { (3) } 3.24 E-10 & \text { (15) } 1.39 E-09 & \text { (9) } 8.98 E-10 & \text { (3) } 5.79 E-10\end{array}$

$\begin{array}{lllllll}\text { (14) } 4.63 E-09 & \text { (8) } 1.09 E-09 & \text { (2) } 2.55 E-10 & \text { (14) } 1.30 E-09 & \text { (8) } 8.35 E-10 & \text { (2) } 5.38 E-10\end{array}$

$\begin{array}{llllll}\text { (13) } 3.63 E-09 & \text { (7) } 8.52 E-10 & \text { (1) } 2.00 E-10 & \text { (13) } 1.20 E-09 & \text { (7) } 7.76 E-10 & \text { (1) } 5.00 E-10\end{array}$

(12) $2.85 E-09 \quad$ (6) $6.69 E-10$

(12) $1.12 E-09$ (6) $7.21 E-10$

(11) $2.24 E-09 \quad$ (5) $5.26 E-10$

(11) $1.04 E-09 \quad$ (5) $6.70 E-10$

(a)

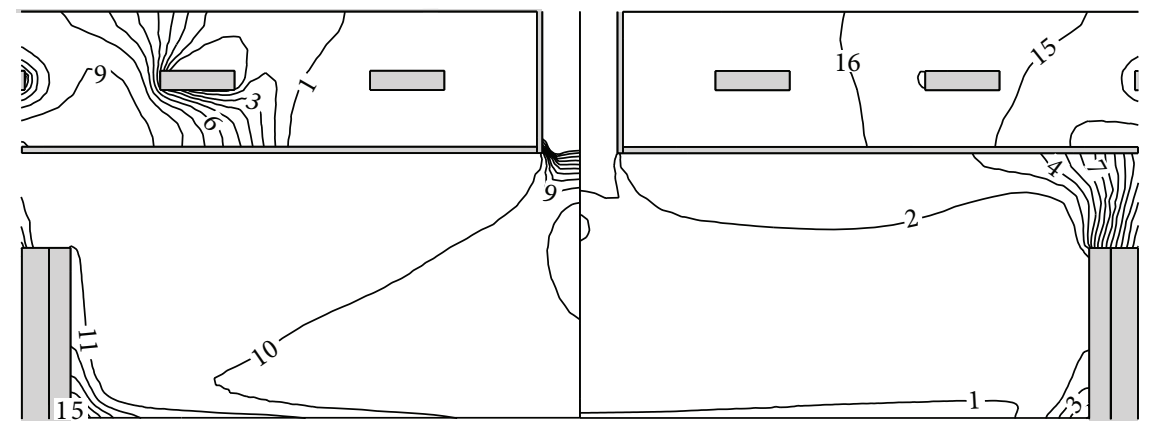

Level of $\mathrm{SiO}\left(\mathrm{mol} / \mathrm{cm}^{3}\right)$

Level of $\mathrm{CO}\left(\mathrm{mol} / \mathrm{cm}^{3}\right)$

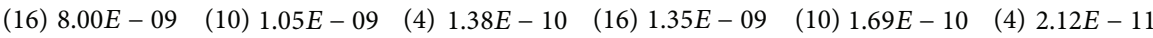

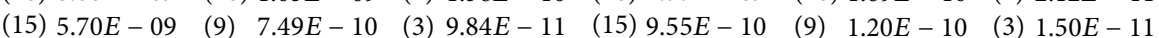

$\begin{array}{lllllll}\text { (14) } 4.07 E-09 & \text { (8) } 5.34 E-10 & \text { (2) } 7.01 E-11 & \text { (14) } 6.76 E-10 & \text { (8) } 8.46 E-11 & \text { (2) } 1.06 E-11\end{array}$

$\begin{array}{llllll}\text { (13) } 2.90 E-09 & \text { (7) } 3.81 E-10 & \text { (1) } 5.00 E-11 & \text { (13) } 4.78 E-10 & \text { (7) } 5.99 E-11 & \text { (1) } 7.50 E-12\end{array}$

(12) $2.07 E-09 \quad$ (6) $2.71 E-10$

(12) $3.38 E-10 \quad(6) \quad 4.23 E-11$

(11) $1.47 E-09 \quad$ (5) $1.94 E-10$

(11) $2.39 E-10 \quad$ (5) $3.00 E-11$

(b)
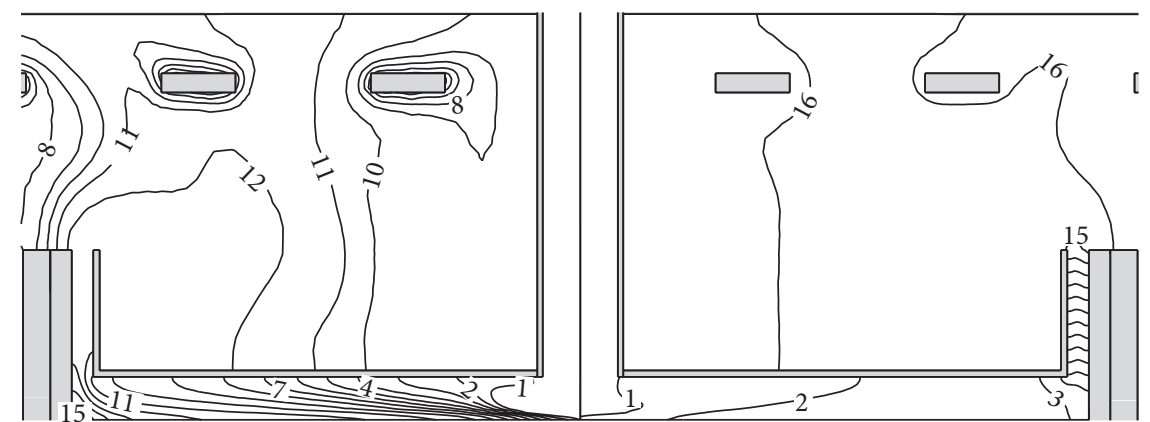

Level of $\mathrm{SiO}\left(\mathrm{mol} / \mathrm{cm}^{3}\right)$

Level of $\mathrm{CO}\left(\mathrm{mol} / \mathrm{cm}^{3}\right)$

$\begin{array}{llllll}\text { (16) } 8.00 E-09 & \text { (10) } 5.52 E-10 & \text { (4) } 3.81 E-11 & \text { (16) } 1.00 E-09 & \text { (10) } 3.98 E-18 & \text { (4) } 1.58 E-26\end{array}$

$\begin{array}{llllll}\text { (15) } 5.12 E-09 & \text { (9) } 3.53 E-10 & \text { (3) } 2.44 E-11 & \text { (15) } 3.98 E-11 & \text { (9) } 1.58 E-19 & \text { (3) } 6.31 E-28\end{array}$

$\begin{array}{llllll}\text { (14) } 3.28 E-09 & \text { (8) } 2.26 E-10 & \text { (2) } 1.56 E-11 & \text { (14) } 1.58 E-12 & \text { (8) } 6.31 E-21 & \text { (2) } 2.51 E-29\end{array}$

$\begin{array}{llllll}\text { (13) } 2.10 E-09 & \text { (7) } 1.45 E-10 & \text { (1) } 1.00 E-11 & \text { (13) } 6.31 E-14 & \text { (7) } 2.51 E-22 & \text { (1) } 1.00 E-30\end{array}$

(12) $1.35 E-09 \quad$ (6) $9.28 E-11$

(12) $2.51 E-15 \quad$ (6) $1.00 E-23$

(11) $8.62 E-10 \quad$ (5) $5.95 E-11$

$\begin{array}{ll}\text { (11) } 1.00 E-16 & \text { (5) } 3.98 E-25\end{array}$

(c)

FIgURE 4: Distributions of $\mathrm{SiO}$ (left) and $\mathrm{CO}$ (right) concentration above the melt free surface for different cover designs without surface reaction: (a) no cover, (b) flat cover, and (c) U cover. 


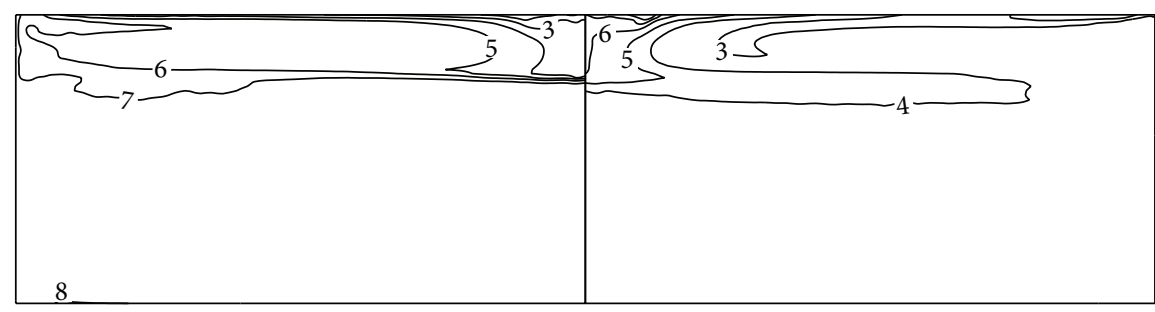

Level of $\mathrm{O}\left(\right.$ atoms $\left./ \mathrm{cm}^{3}\right)$
(8) $8.90 E+17$
(7) $5.80 E+17$
(6) $3.78 E+17$
(5) $2.46 E+17$
(4) $1.60 E+17$
(3) $1.05 E+17$
(2) $6.81 E+16$
(1) $4.44 E+16$

Level of C (atoms $/ \mathrm{cm}^{3}$ )
(8) $3.250 E+19$
(4) $3.215 E+19$
(7) $3.240 E+19$
(6) $3.230 E+19$
(3) $3.212 E+19$
(2) $3.210 E+19$
(5) $3.220 E+19$
(1) $3.200 E+19$

(a)

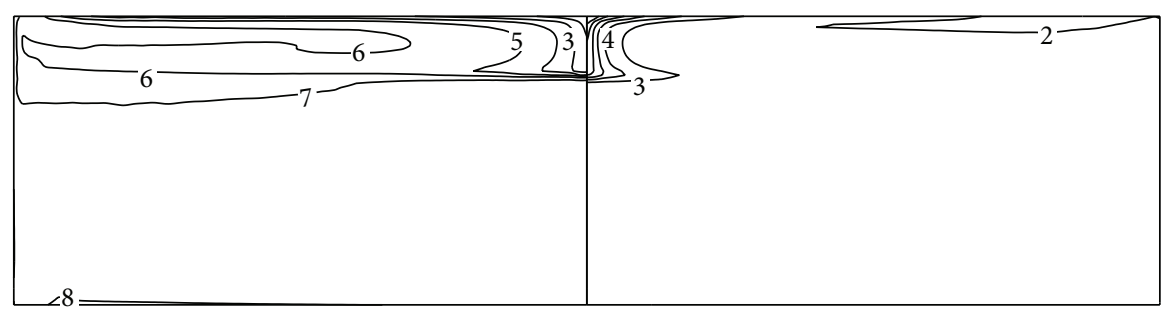

Level of $\mathrm{O}$ (atoms $/ \mathrm{cm}^{3}$ )
(8) $8.90 E+17$
(7) $5.55 E+17$
(6) $3.46 E+17$
(5) $2.16 E+17$
(4) $1.34 E+17$
(3) $8.39 E+16$
(2) $5.23 E+16$
(1) $3.26 E+16$ Level of C (atoms $/ \mathrm{cm}^{3}$ )
(8) $5.00 E+17$
(4) $4.94 E+17$
(7) $4.99 E+17$
(3) $4.93 E+17$
(6) $4.97 E+17$
(2) $4.91 E+17$
(5) $4.96 E+17$
(1) $4.90 E+17$

(b)

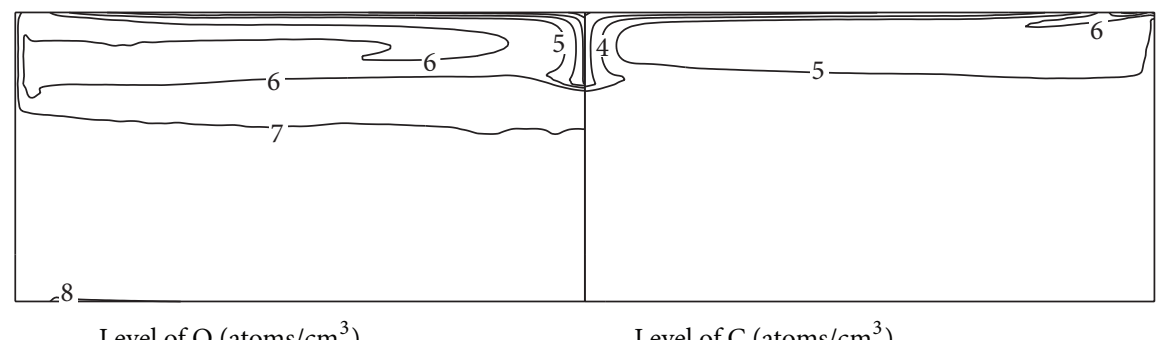
(8) $8.90 E+17$
(4) $1.39 E+17$
(7) $5.59 E+17$
(3) $8.73 E+16$
(6) $3.52 E+17$
(2) $5.49 E+16$
(5) $2.21 E+17$
(1) $3.45 E+16$

Level of C (atoms $/ \mathrm{cm}^{3}$ )

(8) 13.28

(4) 13.23

(7) 13.27

(3) 13.22

(6) 13.26

(2) 13.21

(5) 13.25

(1) 13.20

(c)

FIGURE 5: Distributions of O (left) and C (right) concentration in the silicon melt for different cover designs without surface reaction: (a) no cover, (b) flat cover, and (c) U cover.

free surface and the cover compared with the flat-cover design even with chemical reaction on the cover's surface, as shown in Figure 6. However, the CO concentrations in both Figures 6(a) and 6(b) are higher than those in Figures 4(b) and $4(c)$, respectively, because the crucible cover is another carbon source in the furnace chamber.

Finally, the $\mathrm{O}$ and $\mathrm{C}$ atom distributions in the silicon melt are compared for the different cover designs with chemical reaction on the cover's surface. The concentration of $\mathrm{O}$ is about $10^{16}$ to $10^{17}$ atoms $/ \mathrm{cm}^{3}$ in Figures $7(\mathrm{a})$ and $7(\mathrm{~b})$. This indicates that the cover design has little effect on the oxygen concentration in the silicon melt. However, for the $\mathrm{C}$ distribution, the $\mathrm{U}$-cover design can reduce the concentration by one order of magnitude compared with the flat cover, as shown in Figure 7. Comparing the C concentration in Figure 7(a) with that in Figure 5(a), the graphite flat cover without a coating cannot reduce the $\mathrm{C}$ concentration in the silicon melt. However, for the graphite $U$ cover without a coating, it can still reduce the $\mathrm{C}$ concentration by one order of magnitude compared with the no-cover design by comparison of Figure $7(\mathrm{~b})$ with Figure 5(a). 


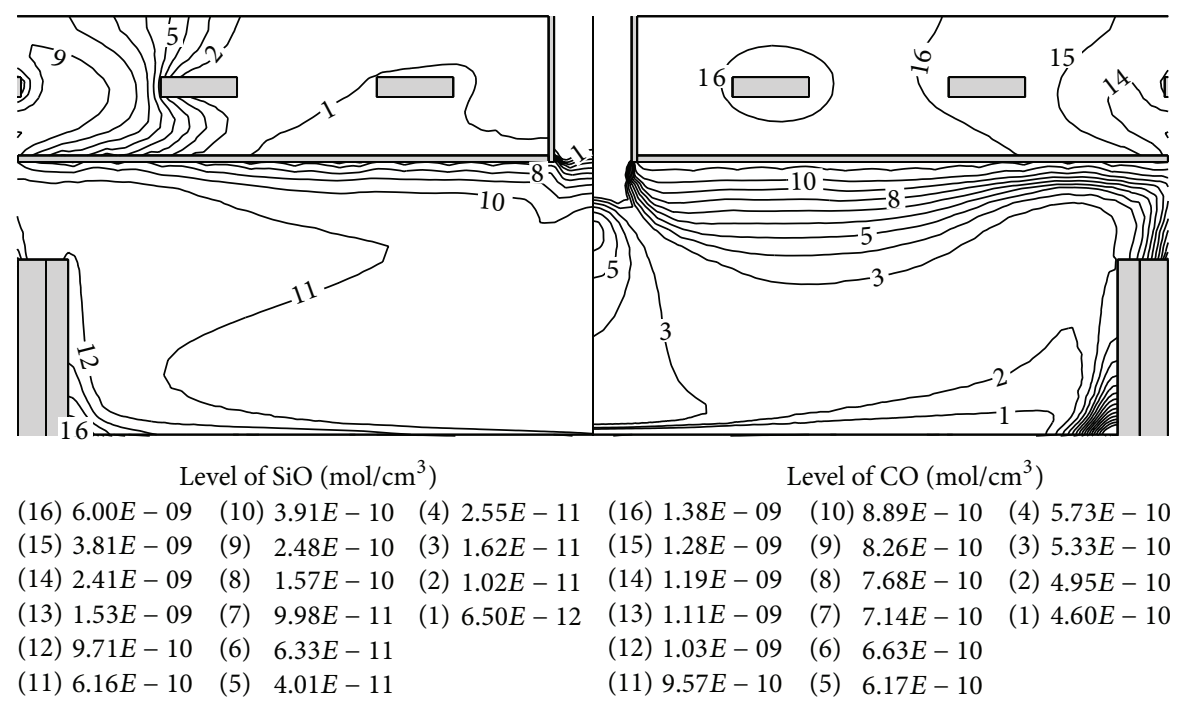

(a)

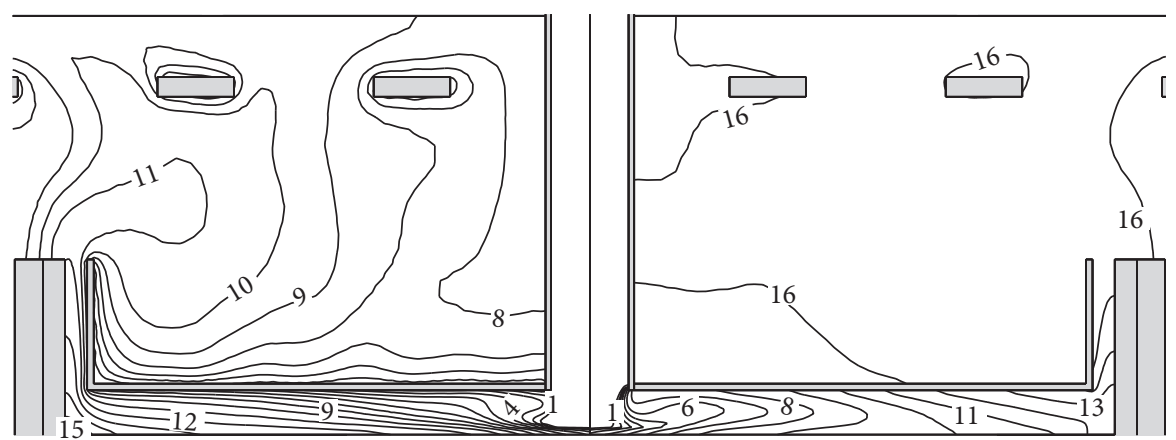

\begin{tabular}{|c|c|c|c|c|c|c|}
\hline \multicolumn{3}{|c|}{ Level of $\mathrm{SiO}\left(\mathrm{mol} / \mathrm{cm}^{3}\right)$} & \multicolumn{4}{|c|}{ Level of $\mathrm{CO}\left(\mathrm{mol} / \mathrm{cm}^{3}\right)$} \\
\hline (16) $8.00 E-09$ & (10) $2.20 E-10$ & (4) $6.03 E-12$ & (16) $1.50 E-09$ & (10) & $3.20 E-11$ & (4) $6.84 E-13$ \\
\hline $4.39 E-09$ & (9) $1.21 E-10$ & (3) $3.31 E-12$ & (15) $7.90 E-10$ & (9) & $1.69 E-11$ & (3) $3.60 E-13$ \\
\hline $2.41 E-09$ & (8) $6.63 E-11$ & (2) $1.82 E-12$ & (14) $4.16 E-10$ & (8) & $8.89 E-12$ & (2) $1.90 E-13$ \\
\hline $1.33 E-09$ & (7) $3.64 E-11$ & (1) $1.00 E-12$ & (13) $2.19 E-10$ & (7) & $4.68 E-12$ & (1) $1.00 E-13$ \\
\hline$E-10$ & (6) $2.00 E-11$ & & (12) $1.15 E-10$ & (6) & $2.47 E-12$ & \\
\hline $4.00 E-10$ & (5) $1.10 E-11$ & & (11) $6.08 E-11$ & (5) & $1.30 E-12$ & \\
\hline
\end{tabular}

(b)

FIGURE 6: Distributions of $\mathrm{SiO}$ (left) and $\mathrm{CO}$ (right) concentration above the melt free surface for different cover designs with surface reaction: (a) flat cover and (b) $U$ cover.

\section{Conclusions}

Global simulations were carried out including all types of heat transfer and coupled oxygen/carbon transport in an industrial DS furnace. Three types of cover design, namely, no-cover, flat-cover, and U-cover designs, were compared to investigate their effect on oxygen and carbon transport during the DS process. The U-cover design can significantly change the argon flow pattern and $\mathrm{SiO}$ distribution above the melt free surface compared with the other two designs, while it had little effect on the $\mathrm{O}$ concentration in the silicon melt. For the carbon impurity, the cover design can significantly influence the $\mathrm{CO}$ distribution above the melt free surface as well as the carbon concentration in the silicon melt. The flat-cover design without chemical reaction on its surface can reduce the $\mathrm{C}$ concentration in the silicon melt by two orders of magnitude compared with the no-cover design. For the U-cover design without chemical reaction on its surface, the silicon melt is almost free of $\mathrm{C}$ contamination. For the graphite covers without a coating, the flat-cover design has little influence on the $\mathrm{C}$ concentration and the $\mathrm{U}$-cover design can reduce the $\mathrm{C}$ concentration in the silicon melt by one order of magnitude compared with the no-cover design. This study may provide a possible way to produce high purity mcSi for solar cells.

\section{Conflict of Interests}

The authors declare that there is no conflict of interests regarding the publication of this paper. 


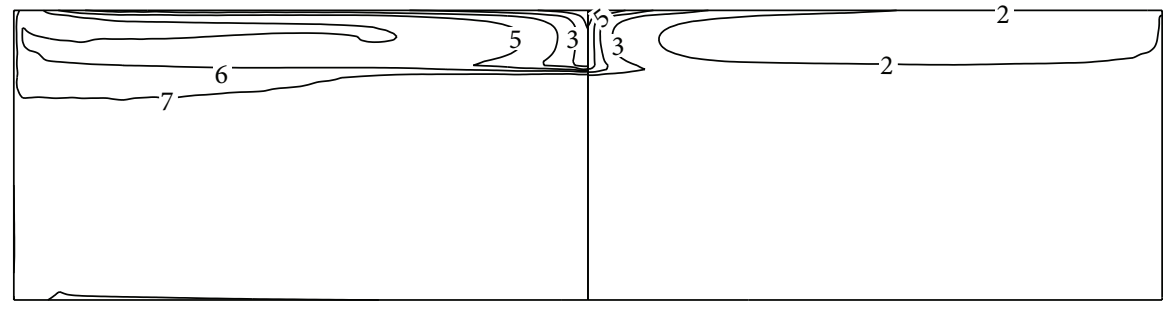

Level of $\mathrm{O}$ (atoms $/ \mathrm{cm}^{3}$ )
(8) $8.90 E+17$
(7) $5.48 E+17$
(6) $3.38 E+17$
(5) $2.08 E+17$
(4) $1.28 E+17$
(3) $7.90 E+16$
(2) $4.87 E+16$
(1) $3.00 E+16$

Level of C (atoms $\left./ \mathrm{cm}^{3}\right)$
(8) $3.70 E+19$
(4) $3.66 E+19$
(7) $3.69 E+19$
(6) $3.68 E+19$
(3) $3.65 E+19$
(2) $3.64 E+19$
(5) $3.67 E+19$
(1) $3.63 E+19$

(a)

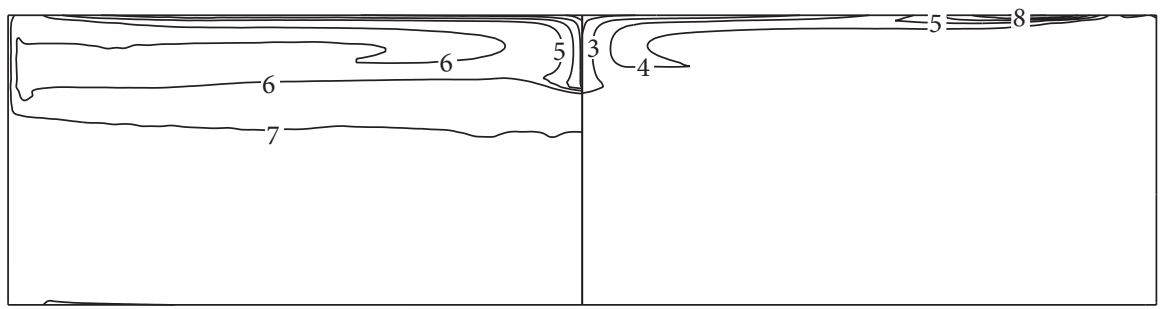

Level of $\mathrm{O}\left(\mathrm{atoms} / \mathrm{cm}^{3}\right)$
(8) $8.90 E+17$
(7) $5.59 E+17$
(6) $3.51 E+17$
(5) $2.20 E+17$
(4) $1.38 E+17$
(3) $8.68 E+16$
(2) $5.45 E+16$
(1) $3.42 E+16$

Level of C (atoms $/ \mathrm{cm}^{3}$ )
(8) $3.302 E+18$
(4) $3.293 E+18$
(7) $3.300 E+18$
(6) $3.298 E+18$
(5) $3.296 E+18$
(3) $3.291 E+18$
(2) $3.289 E+18$
(1) $3.287 E+18$

(b)

FIGURE 7: Distributions of O (left) and C (right) concentration in the silicon melt for different cover designs with surface reaction: (a) flat cover and (b) U cover.

\section{Acknowledgments}

This work was supported by the National Natural Science Foundation of China (nos. 51176148 and 51406156) and Fundamental Research Funds for the Central Universities of China.

\section{References}

[1] T. Saitoh, X. Wang, H. Hashigami et al., "Suppression of light degradation of carrier lifetimes in low-resistivity CZ-Si solar cells," Solar Energy Materials and Solar Cells, vol. 65, no. 1, pp. 277-285, 2001.

[2] D. E. Bornside, R. A. Brown, T. Fujiwara, H. Fujiwara, and T. Kubo, "Effects of gas-phase convection on carbon contamination of Czochralski-grown silicon," Journal of the Electrochemical Society, vol. 142, no. 8, pp. 2790-2804, 1995.

[3] M. Trempa, C. Reimann, J. Friedrich, and G. Müller, "The influence of growth rate on the formation and avoidance of $\mathrm{C}$ and $\mathrm{N}$ related precipitates during directional solidification of multi crystalline silicon," Journal of Crystal Growth, vol. 312, no. 9, pp. 1517-1524, 2010.

[4] C. Reimann, M. Trempa, T. Jung, J. Friedrich, and G. Müller, "Modeling of incorporation of $\mathrm{O}, \mathrm{N}, \mathrm{C}$ and formation of related precipitates during directional solidification of silicon under consideration of variable processing parameters," Journal of Crystal Growth, vol. 312, no. 7, pp. 878-885, 2010.

[5] B. Gao, S. Nakano, and K. Kakimoto, "Reduction of oxygen impurity in multicrystalline silicon production," International Journal of Photoenergy, vol. 2013, Article ID 908786, 6 pages, 2013.

[6] B. Gao, S. Nakano, and K. Kakimoto, "Global simulation of coupled carbon and oxygen transport in a unidirectional solidification furnace for solar cells," Journal of the Electrochemical Society, vol. 157, no. 2, pp. H153-H159, 2010.

[7] Z. Y. Li, L. J. Liu, W. C. Ma, and K. Kakimoto, "Effects of argon flow on impurities transport in a directional solidification furnace for silicon solar cells," Journal of Crystal Growth, vol. 318, no. 1, pp. 304-312, 2011.

[8] Y.-Y. Teng, J.-C. Chen, C.-W. Lu, H.-I. Chen, C. Hsu, and C.-Y. Chen, "Effects of the furnace pressure on oxygen and silicon oxide distributions during the growth of multicrystalline silicon ingots by the directional solidification process," Journal of Crystal Growth, vol. 318, no. 1, pp. 224-229, 2011.

[9] B. Gao, X. J. Chen, S. Nakano, and K. Kakimoto, "Crystal growth of high-purity multicrystalline silicon using a unidirectional solidification furnace for solar cells," Journal of Crystal Growth, vol. 312, no. 9, pp. 1572-1576, 2010.

[10] X. Ma, L. Zheng, H. Zhang, B. Zhao, C. Wang, and F. Xu, "Thermal system design and optimization of an industrial 
silicon directional solidification system," Journal of Crystal Growth, vol. 318, no. 1, pp. 288-292, 2011.

[11] Y.-Y. Teng, J.-C. Chen, C.-W. Lu, and C.-Y. Chen, "Numerical investigation of oxygen impurity distribution during multicrystalline silicon crystal growth using a gas flow guidance device," Journal of Crystal Growth, vol. 360, no. 1, pp. 12-17, 2012.

[12] M. P. Bellmann, D. Lindholm, and M. M'Hamdi, “A novel method for gas flow and impurity control in directional solidification of multi-crystalline silicon," Journal of Crystal Growth, vol. 399, pp. 33-38, 2014.

[13] X. Liu, B. Gao, and K. Kakimoto, "Numerical investigation of carbon contamination during the melting process of Czochralski silicon crystal growth," Journal of Crystal Growth, vol. 417, pp. 58-64, 2014.

[14] L. J. Liu and K. Kakimoto, "Partly three-dimensional global modeling of a silicon Czochralski furnace. I. Principles, formulation and implementation of the model," International Journal of Heat and Mass Transfer, vol. 48, no. 21-22, pp. 4481-4491, 2005.

[15] L. J. Liu, S. Nakano, and K. Kakimoto, "Investigation of oxygen distribution in electromagnetic CZ-Si melts with a transverse magnetic field using 3D global modeling," Journal of Crystal Growth, vol. 299, no. 1, pp. 48-58, 2007.

[16] H. Matsuo, R. B. Ganesh, S. Nakano et al., "Thermodynamical analysis of oxygen incorporation from a quartz crucible during solidification of multicrystalline silicon for solar cell," Journal of Crystal Growth, vol. 310, no. 22, pp. 4666-4671, 2008. 

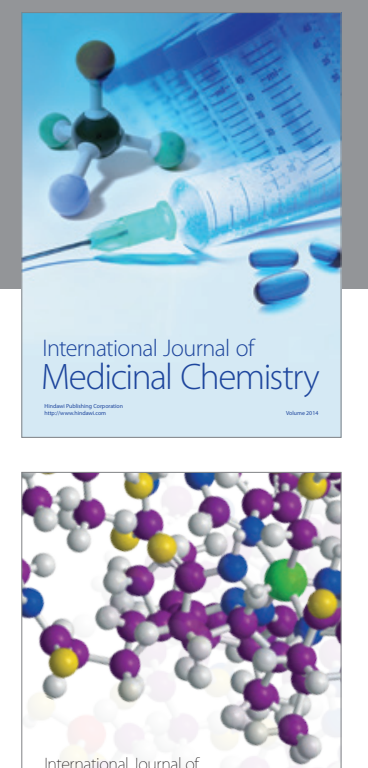

\section{Carbohydrate} Chemistry

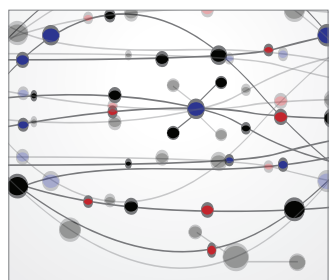

The Scientific World Journal
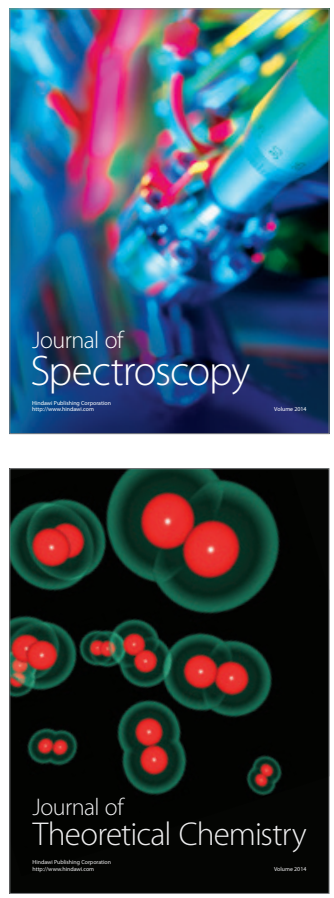
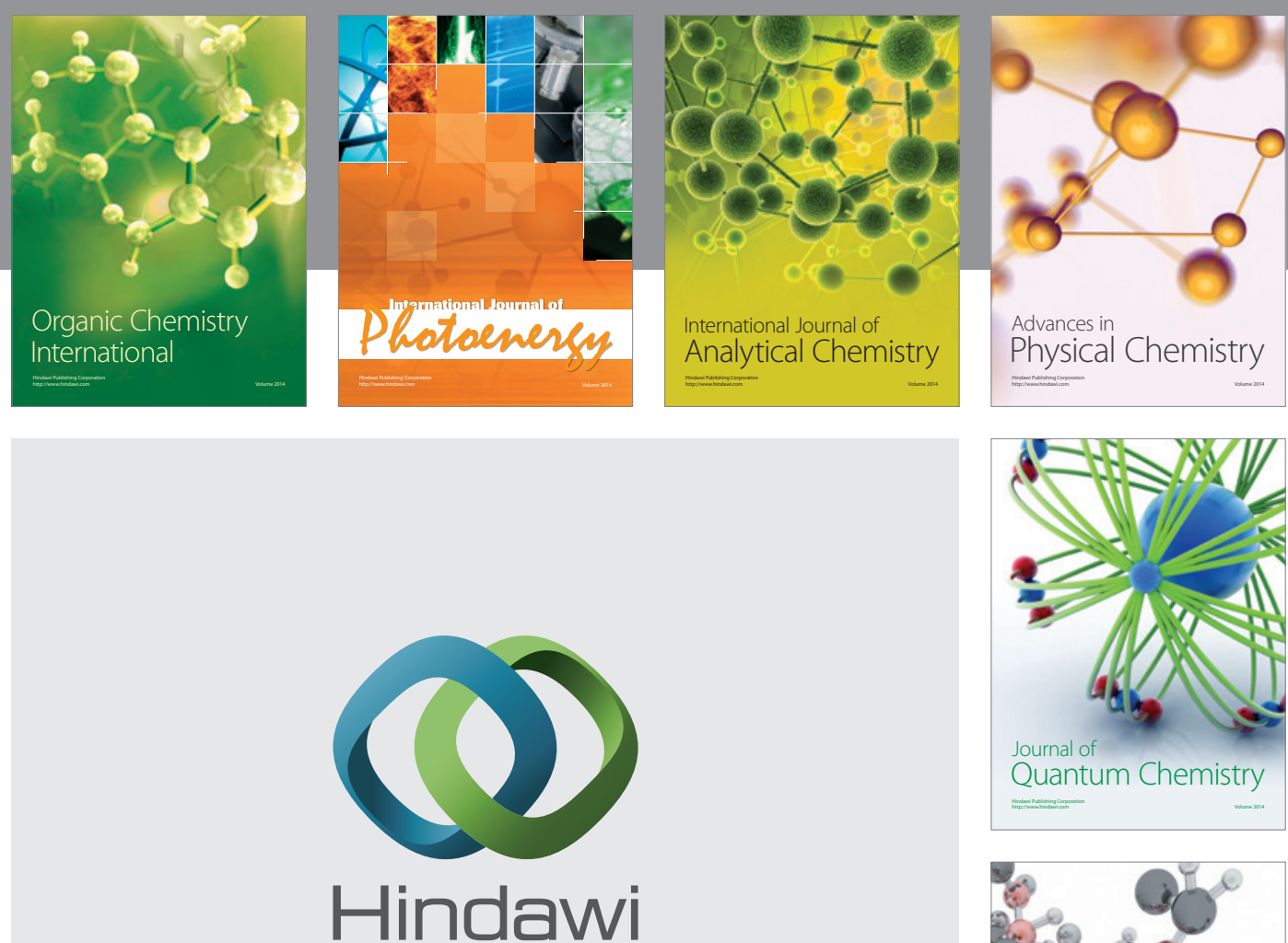

Submit your manuscripts at

http://www.hindawi.com

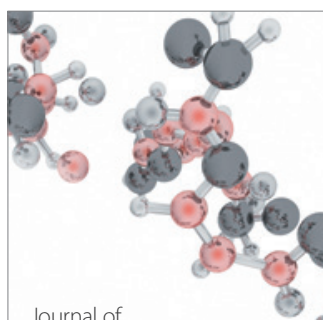

Analytical Methods

in Chemistry

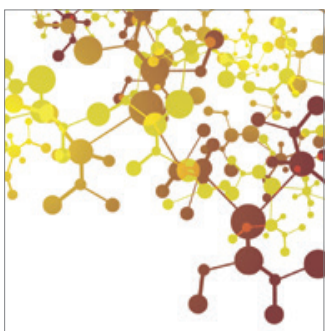

Journal of

Applied Chemistry

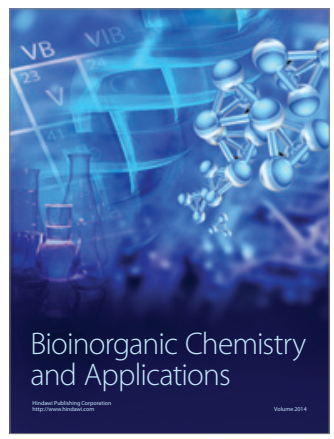

Inorganic Chemistry
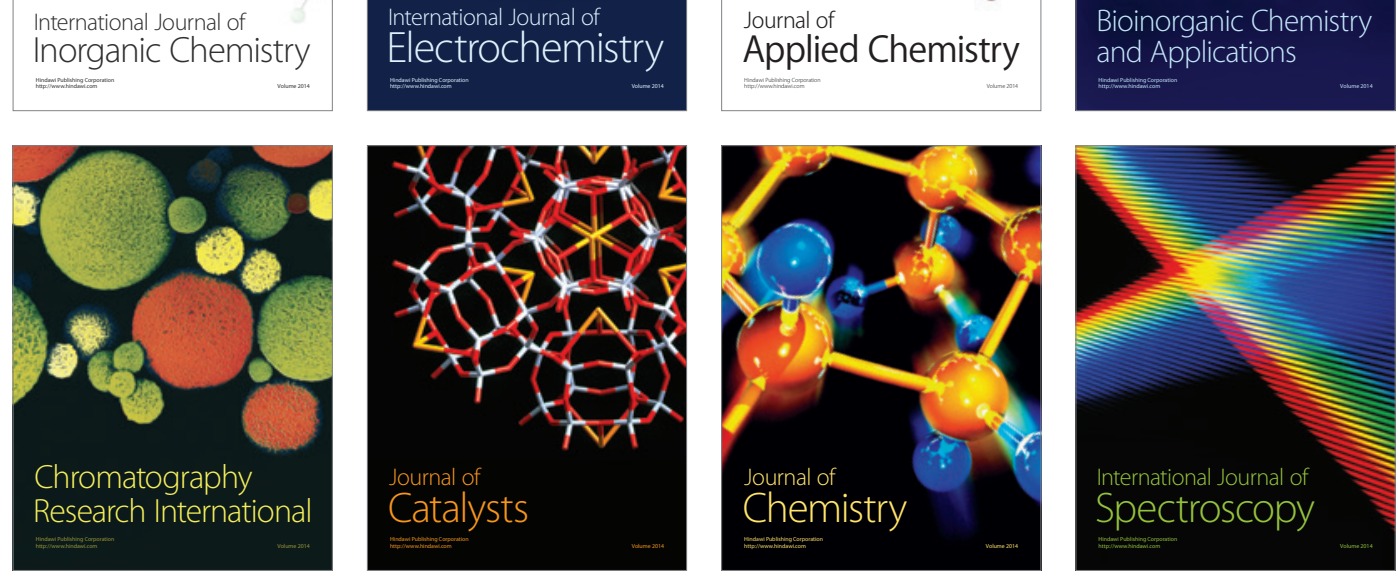